\title{
Prime-boost vaccination targeting prostatic acid phosphatase (PAP) in patients with metastatic castration-resistant prostate cancer (mCRPC) using Sipuleucel-T and a DNA vaccine
}

Ellen Wargowski ${ }^{1}$, Laura E. Johnson ${ }^{1}$, Jens C. Eickhoff1,2, Lauren Delmastro ${ }^{1}$, Mary Jane Staab ${ }^{1}$, Glenn Liu ${ }^{1}$ and Douglas G. McNeel ${ }^{1 *}$

\begin{abstract}
Background: Prostatic acid phosphatase (PAP) is a prostate tumor antigen, and the target of the only FDA-approved anti-tumor vaccine, sipuleucel-T. We have previously reported in two clinical trials that a DNA vaccine encoding PAP (pTVG-HP) could elicit PAP-specific, Th1-biased T cells in patients with PSA-recurrent prostate cancer. In the current pilot trial we sought to evaluate whether this vaccine could augment PAP-specific immunity when used as a booster to immunization with sipuleucel-T in patients with metastatic, castration-resistant prostate cancer (MCRPC).

Methods: Eigthteen patients with MCRPC were randomized to receive sipuleucel-T alone or followed by intradermal immunization with pTVG-HP DNA vaccine. Patients were followed for time to progression, and immune monitoring was conducted at defined intervals.

Results: Overall, patients were followed for a median of 24 months. 11/18 patients completed treatments as per protocol. No treatment-associated events > grade 2 were observed. Th1-biased PAP-specific T-cell responses were detected in 11/18 individuals, and were not statistically different between study arms. Higher titer antibody responses to PAP were detectable in patients who received pTVG-HP booster immunizations. Median time to progression was less than 6 months and not statistically different between study arms. The median overall survival for all patients was 28 months.
\end{abstract}

Conclusions: These findings suggest that prime-boost vaccination can augment and diversify the type of immunity elicited with anti-tumor vaccination in terms of T-cell and humoral immunity. Future studies will explore DNA as priming immunization rather than a booster immunization.

Trial registration: NCT01706458.

Keywords: Sipuleucel-T, DNA vaccine, Prostate cancer, Prostatic acid phosphatase, Immune monitoring, Clinical trial

\footnotetext{
* Correspondence: dm3@medicine.wisc.edu

'University of Wisconsin Carbone Cancer Center, 1111 Highland Avenue,

Madison, WI 53705, USA

Full list of author information is available at the end of the article
} 


\section{Background}

Sipuleucel-T was approved by the U.S. Food and Drug Administration (FDA) for the treatment of patients with metastatic, castration-resistant prostate cancer based on data from a randomized clinical trial demonstrating an improvement in overall survival compared to placebo [1]. While the median improvement in overall survival was only 4 months, this is as comparable to other agents that have been approved for this stage of prostate cancer, including docetaxel [2, 3], cabazitaxel [4], abiraterone [5], radium-223 [6], and enzalutamide [7]. Subsequent retrospective studies have suggested that patients with lower burdens of disease, and those who developed evidence of immunity to the prostatic acid phosphatase (PAP) target antigen with either antigen-specific IgG or $\mathrm{T}$ cells, might have had a superior outcome in terms of longer overall survival $[8,9]$. Consequently, these findings suggest that the target of this vaccine, PAP, is a rational vaccine target antigen for prostate cancer treatment. Moreover, these findings suggest that using combination vaccine approaches to increase the immunological activity of sipuleucel-T to PAP might lead to superior clinical outcomes.

We have evaluated PAP-targeted vaccines using plasmid DNA as the means of antigen delivery [10]. In two phase I trials evaluating dose and schedule in patients with nonmetastatic prostate cancer (castration-sensitive and castration-resistant), we found vaccination to be safe and able to elicit PAP-specific CD4+ and CD8+ T cells with a Th1 phenotype $[11,12]$. Unlike results from trials using sipuleucel-T, DNA vaccination did not elicit PAP-specific antibodies in either trial. The frequency of PAP-specific $\mathrm{T}$ cells was augmented with subsequent immunization, and the development of durable Th1-biased immune responses (detectable up to one year after treatment) appeared to be associated with favorable changes in PSA doubling time $[12,13]$. Based on these results, a randomized phase II trial evaluating this vaccine is currently underway to determine whether treatment can delay the time to development of metastases in patients with biochemically recurrent prostate cancer (NCT01341652).

The ability of a DNA vaccine to elicit and augment Th1biased immunity to PAP suggests it might be useful in a prime-boost strategy with sipuleucel-T, particularly since both vaccines target the same PAP antigen. Given that sipuleucel-T is an approved therapy delivered three times at two-week intervals, we sought to evaluate an approach in which DNA immunization was delivered after sipuleucel-T, as a booster immunization. We describe here the results of a pilot randomized clinical trial (NCT01706458) in which patients with mCRPC received sipuleucel-T alone (3 times at 2-week intervals), or sipuleucel-T (3 times at 2-week intervals) followed by DNA immunization 4 times at 2-week intervals, and then at months 6 and 9 after study initiation. The primary endpoint of the study was to determine if DNA vaccination could augment PAP-specific effector and memory T cells following treatment with sipuleucel-T. Secondary and exploratory objectives included effects on other measures of immunity, progression-free survival, and overall survival.

\section{Methods}

\section{Investigational agent and regulatory information}

pTVG-HP is a plasmid DNA encoding the full-length human PAP (ACPP gene) cDNA downstream of a eukaryotic promoter [14]. The study protocol was reviewed and approved by all local (University of Wisconsin Human Subjects' Review Board), and federal (FDA, NIH Recombinant DNA Advisory Committee) entities. All patients gave written informed consent for participation.

\section{Patient population}

Male patients with a histological diagnosis of prostate adenocarcinoma and PSA recurrence following castration (surgical or ongoing luteinizing hormone-releasing hormone agonist therapy) were eligible, provided they had evidence of metastatic disease by CT of abdomen/pelvis and/or bone scintigraphy. Progressive disease following the last treatment was required, as per Prostate Cancer Working Group 2 criteria [15], and patients were required to be at least 4 weeks from prior treatment. A minimum of three PSA values, obtained from the same clinical laboratory over at least a 12-week period of time prior to registration, was required to calculate a PSA doubling time. Patients were required to have an Eastern Cooperative Oncology Group performance score of $\leq 2$, and normal bone marrow, liver and renal function as defined by a WBC $\geq 2000$ / $\mu \mathrm{L}, \mathrm{ANC} \geq 1000 / \mathrm{mm}^{3}$, hemoglobin $\geq 9.0 \mathrm{~g} / \mathrm{dL}$, platelet count $\geq 100,000 / \mu \mathrm{L}$, AST and ALT $\leq 2.5 \times$ institutional upper limit of normal, and serum creatinine $<2.0 \mathrm{mg} / \mathrm{dL}$. Patients were excluded if they had symptomatic disease (defined as requiring opioid analgesics for the treatment of pain attributed to a metastatic lesion), or been treated with chemotherapy within 6 months, or radiation therapy or systemic corticosteroid therapy $(\geq 1 \mathrm{mg}$ dose equivalent prednisone daily) within 4 weeks, of registration. Patients were further excluded if they had a history of HIV, hepatitis $\mathrm{B}$, or hepatitis $\mathrm{C}$ infection, or if they had received prior sipuleucel-T treatment.

\section{Study design and procedures}

This study was an open-label, single institution, two-arm pilot trial (Fig. 1). The primary endpoint was to determine if booster immunizations could augment the antigenspecific T-cell immune response rate. The accrual goal was 28 patients to identify an increase in immune response rate by $50 \%$ with $\geq 80 \%$ power at a one-sided $5 \%$ significance level. Subjects in Arm 1 received sipuleucel-T as per 


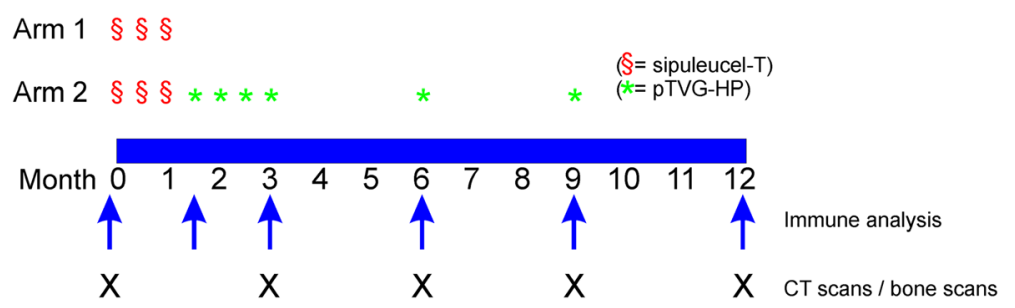

Fig. 1 Trial Schema. Trial schema with schedules of vaccine administrations, immune analysis, and clinical staging evaluations, indicated

standard of care, three times at two-week intervals. Subjects in Arm 2 received sipuleucel-T as per standard of care, three times at two-week intervals, and then received four biweekly immunizations with pTVG-HP (100 $\mu \mathrm{g}$ per immunization, co-administered intradermally with $200 \mu \mathrm{g}$ GM-CSF adjuvant (sargramostim, Genzyme, Cambride, MA) at weeks $6,8,10$, and 12 , and then further immunizations at months 6 and 9. DNA immunizations were delivered as an intradermal injection in the deltoid region with a 28-guage needle and syringe. Patients underwent a leukapheresis procedure within two weeks prior to the first sipuleucel-T product collection and at month 6 for immunological monitoring. Additional $100 \mathrm{~mL}$ blood draws were performed at weeks 6, 12, and month 9 and 12 for immunological monitoring. All subjects were followed for at least one year, with staging CT scans of the abdomen and pelvis, and bone scintigraphy, performed every 12 weeks. Patients remained in long-term follow-up for up to five years to identify any potential long-term risks. Patients came off study at month 12 , at the time of radiographic progression, at any time of undue toxicity, or at the discretion of the patient or treating physician that other therapies for prostate cancer were warranted. In order to account for possible delayed treatment effects, patients did not come off trial for radiographic progression at week 12 unless there was symptomatic progression requiring new therapy. Radiographic progression was defined using modified RECIST/PCWG2 criteria, however using scans obtained at week 12 as the baseline study for comparison. Patients also received a tetanus immunization immediately following the baseline leukapheresis. Blood tests were performed every 6-12 weeks and included $\mathrm{CBC}$, creatinine, SGOT, alkaline phosphatase, amylase, LDH, bilirubin, serum PAP, and serum PSA. Serum testosterone was performed at baseline to confirm that patients were functionally castrate (testosterone levels $<50 \mathrm{ng} / \mathrm{mL}$ ). All toxicities were graded according to the NCI Common Terminology Criteria Grading System, version 3.

\section{Immune analyses}

For each time point, measures of antigen-specific T-cell immunity were performed with fresh (not cryopreserved) peripheral blood mononuclear cells (PBMC), and without in vitro stimulation prior to analysis. ELISPOT for IFN $\gamma$ and granzyme B release were performed as previously described in 8-well replicates [12]. For these analyses, protein antigens (PAP (Fitzgerald Industries, Acton, MA), PSA (Fitzgerald), tetanus toxoid (EMD Millipore, Billerica, MA), and GM-CSF (Leukine, Sanofi, Bridgewater, NJ)) and human $\mathrm{AB}$ serum (Valley Biomedical, Winchester, VA) used were from the same lots to control for possible variation over time. A response resulting from immunization was defined as a PAP-specific response detectable more than once post-treatment that was both significant (compared to media only control), at least 3-fold higher than the pre-treatment value, and with a frequency $>$ 1:100,000 PBMC. For peptide-specific evaluation over time, cryopreserved PBMC were thawed, stimulated in vitro with $0.5 \mu \mathrm{g} / \mathrm{mL}$ of peptide for 7-11 days, washed, and then evaluated by ELISPOT as indicated above. IgG specific for PAP, PSA, GM-CSF or tetanus toxoid were evaluated by indirect ELISA, as previously described [16]. Peptide arrays (RocheNimblegen, Madison, WI) containing 16-mer peptides spanning the amino acid sequence of PAP, overlapping by 4 amino acids, were screened for IgG antibody responses, using sera diluted 1:100 from pre-treatment or 6-month blood collections, and assessed for mean fluorescence to each peptide, as previously reported [17].

\section{Clinical response evaluation}

Staging studies (CT of abdomen/pelvis and bone scintigraphy) were performed every 12 weeks, or as clinically indicated. PSA values were collected from the same clinical laboratory at 6-12 week intervals. A minimum of three PSA values collected over a 12-week period of time, with PSA values up to 6 months, and including the screening value, was used to determine the pre-treatment PSA DT. All values collected on study up to 6 months were used to determine the post-treatment PSA DT. PSA DT was calculated as $\log (2)$ divided by the slope parameter estimate of the linear regression model of the log-transformed PSA values on time.

\section{Statistical analysis}

Demographic characteristics and clinical outcomes were summarized in frequencies and percentages or medians and ranges. Immunological parameters were analyzed descriptively and displayed in graphic format using profile 
Table 1 Demographics. Demographics for all patients enrolled

\begin{tabular}{|c|c|c|c|}
\hline & \multicolumn{2}{|l|}{ Treatment Arm } & \multirow[b]{2}{*}{ Overall } \\
\hline & $1(n=9)$ & $2(n=9)$ & \\
\hline \multicolumn{4}{|l|}{ Age (years) } \\
\hline Median (range) & $75(67-82)$ & $72(66-85)$ & $74(66-85)$ \\
\hline \multicolumn{4}{|l|}{ Race $(n, \%)$} \\
\hline White / Caucasian & $9(100 \%)$ & $9(100 \%)$ & $18(100 \%)$ \\
\hline \multicolumn{4}{|c|}{ ECOG Performance Status (n, \%) } \\
\hline 0 & $9(100 \%)$ & $8(89 \%)$ & $17(94 \%)$ \\
\hline 1 & $0(0 \%)$ & $1(11 \%)$ & $1(6 \%)$ \\
\hline \multicolumn{4}{|l|}{ Gleason score (n, \%) } \\
\hline$<7$ & $1(11 \%)$ & $2(22 \%)$ & $3(17 \%)$ \\
\hline 7 & $3(33 \%)$ & $4(44 \%)$ & $7(39 \%)$ \\
\hline 8 & $0(0 \%)$ & $2(22 \%)$ & $2(11 \%)$ \\
\hline$\geq 9$ & $5(56 \%)$ & $0(0 \%)$ & $5(28 \%)$ \\
\hline Unknown & $0(0 \%)$ & $1(11 \%)$ & $1(6 \%)$ \\
\hline \multicolumn{4}{|l|}{ Metastatic sites (n, \%) } \\
\hline Visceral & $2(22 \%)$ & $0(0 \%)$ & $2(11 \%)$ \\
\hline Bone & $2(22 \%)$ & $5(56 \%)$ & $7(39 \%)$ \\
\hline Distant lymph nodes & $6(67 \%)$ & $4(44 \%)$ & $10(56 \%)$ \\
\hline \multicolumn{4}{|l|}{ Baseline PSA (ng/mL) } \\
\hline Median (range) & $32.6(4.17-1090)$ & $11.2(2.09-68.4)$ & 16.25 (2.09-1090), \\
\hline \multicolumn{4}{|c|}{ Baseline PSA doubling time (months) } \\
\hline Median (range) & $2.8(1.4-63.9)$ & $2.2(1.0-25.8)$ & $2.55(1.0-63)$. \\
\hline
\end{tabular}

plots. Time to radiographic progression and overall survival were analyzed using the Kaplan-Meier method and compared between arms using the log-rank test. Statistical analyses were conducted using SAS software version 9.2 (SAS Institute Inc., Carey, NC).

\section{Results}

Patient population and course of study

Eithteen patients were enrolled in this trial between 2013 and 2016 at the University of Wisconsin Carbone Cancer Center. The median age of participants was 74 years (range 66-85 years), the median serum PSA at the time of study entry for all participants was $16.25 \mathrm{ng} / \mathrm{mL}$ (range 2.09$1090 \mathrm{ng} / \mathrm{mL}$ ), and the median pre-treatment PSA DT for all patients was 2.55 months (range 1.0-63.9 months). Other demographics are shown in Table 1. Two patients in Arm 1 had visceral disease, which was slightly imbalanced relative to Arm 2. As shown in Table 2, few treatment associated adverse events were observed, and no events were greater than grade 2 . Most events were grade 1 or grade 2 flu-like events of limited duration typical for vaccines, including chills, fatigue, fever, and headache. The majority of patients receiving the DNA vaccine experienced grade 1 injection site reactions. Progression was defined as radiographic progression after the first 3-month staging evaluation, and patients were not to be removed from study on the basis of PSA rise only. No patients came off trial due to toxicity. However, 6 patients (3 in each study arm) came off study prior to 6 months at physicians' discretion for clinical progression requiring other therapies. All patients received all sipuleucel-T infusions, however one patient in Arm 2 (ID012) came off study for symptomatic deterioration prior to receiving any DNA vaccine. Patients were followed for 2 years following study completion, and the median length of follow-up for all patients was 24 months. The trial was closed before it reached its accrual goal of 28 patients due to slow accrual and that it appeared unlikely to meet its primary immunological endpoint.

\section{Immunological evaluation}

The primary immunological goal of this study was to determine whether booster immunizations with a DNA vaccine encoding PAP could augment the number of PAPspecific effector and memory $\mathrm{T}$ cells following treatment with sipuleucel-T, or prolong the duration of detectable T-cell response. All subjects received a tetanus booster immunization prior to beginning the immunization series, providing a separate test of an individual's immune responsiveness [12]. Responses to PSA, a non-target prostatespecific protein, were concurrently evaluated, as were 
Table 2 Adverse events. All adverse events at least possibly attributed to study treatment are shown. Numbers represent the number of patients per arm experience a particular event at any point during the treatment period, with the highest grade reported for any single individual. Adverse event grade is according to NCI CTCAE v.3

\begin{tabular}{|c|c|c|c|c|c|c|}
\hline & \multicolumn{2}{|l|}{ Grade 1} & \multicolumn{2}{|c|}{ Grade 2} & \multicolumn{2}{|c|}{ Grade 3-5 } \\
\hline & Arm 1 & Arm 2 & Arm 1 & Arm 2 & Arm 1 & Arm 2 \\
\hline \multicolumn{7}{|l|}{ General / Constitutional } \\
\hline Chills & $3(33 \%)$ & $1(11 \%)$ & & $1(11 \%)$ & & \\
\hline Fatigue & $2(22 \%)$ & $2(22 \%)$ & & $1(11 \%)$ & & \\
\hline Fever & $1(11 \%)$ & $1(11 \%)$ & & & & \\
\hline Malaise & & $1(11 \%)$ & & & & \\
\hline Pain & & $2(22 \%)$ & & & & \\
\hline Headache & & $3(33 \%)$ & & & & \\
\hline Injection site reaction & & $6(67 \%)$ & & & & \\
\hline \multicolumn{7}{|l|}{ Gastrointestinal } \\
\hline Nausea & $3(33 \%)$ & $3(33 \%)$ & & & & \\
\hline Diarrhea & & $1(11 \%)$ & & & & \\
\hline \multicolumn{7}{|l|}{ Vascular } \\
\hline Hypertension & $1(11 \%)$ & & & & & \\
\hline Hot flashes & & $1(11 \%)$ & & & & \\
\hline \multicolumn{7}{|l|}{ Hematologic } \\
\hline Anemia & & $1(11 \%)$ & & & & \\
\hline \multicolumn{7}{|l|}{ Metabolism } \\
\hline Anorexia & & $1(11 \%)$ & & & & \\
\hline \multicolumn{7}{|l|}{ Musculoskeletal } \\
\hline Arthralgia & & $1(11 \%)$ & & & & \\
\hline Back pain & & & & $1(11 \%)$ & & \\
\hline Myalgia & & $1(11 \%)$ & & & & \\
\hline Pain in extremity & & $1(11 \%)$ & & & & \\
\hline
\end{tabular}

responses to GM-CSF, a component of the PA2024 fusion protein used in the preparation of sipuleucel-T. Samples were evaluated for antigen-specific IFNy or granzyme B secretion by ELISPOT, and the detection of statistically significant antigen-specific responses, that were at least 3-fold over the baseline value, and detectable more than once post-treatment, were used to define immune response to a particular antigen, as previously reported [12]. An example of these analyses conducted over time for one individual treated with sipuleucel-T alone (Arm 1) is shown in Fig. 2. In this individual, PAP-specific, tetanus-specific, and GMCSF-specific IFNY (Fig. 2a) and/or granzyme B (Fig. 2b) was detected. A summary of IFN $\gamma$ and granzyme $B$ response for all patients is shown in Fig. 2c. As shown, 11/ 18 (61\%) individuals developed PAP-specific IFNY and/or granzyme $\mathrm{B}$-secreting $\mathrm{T}$-cell responses that were detectable at least twice in follow-up. Of these, 6 were in Arm 1, and 5 were in Arm 2 (with DNA vaccine), and hence a higher immune response rate was not detected in patients receiving both vaccines. 11/16 (69\%) developed GM-CSF-specific IFN $\gamma$ - and/or granzyme B-secreting $\mathrm{T}$-cell responses that were detectable at least twice in follow up. Of note, 6/16 (38\%) individuals developed persistent immunity to GM-CSF but not PAP. Responses to tetanus toxoid were predominantly IFN $\gamma$-biased, as we have previously demonstrated [12]. T-cell responses to PSA were rare $(1 / 18,5 \%)$ as expected.

In two previous trials using pTVG-HP, we have found that immune responses elicited are Th1 biased, and IgG antibody responses to PAP were not elicited [11, 12]. IgG antibody responses to PAP have been detected, however, following treatment with sipuleucel-T $[1,8]$. Consequently, we tested for IgG responses to the same antigens described above (PAP, PSA, tetanus toxoid and GM-CSF). As shown in Fig. 3a for two individual patients treated in Arm 2 with both vaccines, IgG responses to PAP were elicited, in one case peaking at week 6 after treatment with sipuleucel-T and then decreasing in titer, and in the other case not detectable until month 3. IgG titers to all test antigens are shown in Fig. 3b. As expected, antibodies were elicited to tetanus in patients treated on both study arms, and antibody responses to PSA were rare. Antibody responses were 


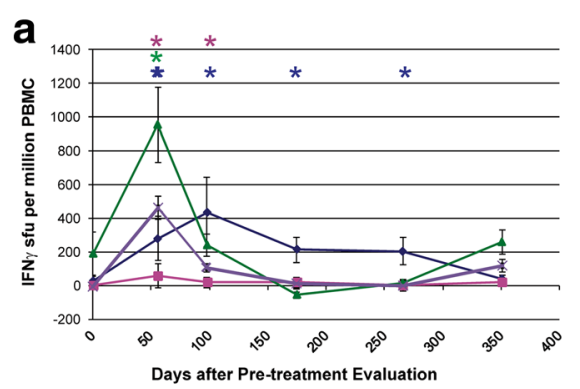

c

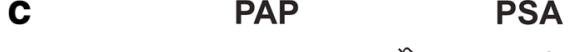

b

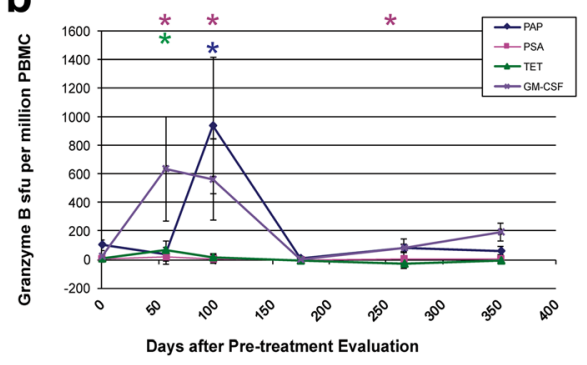

GM-CSF Tetanus Toxoid
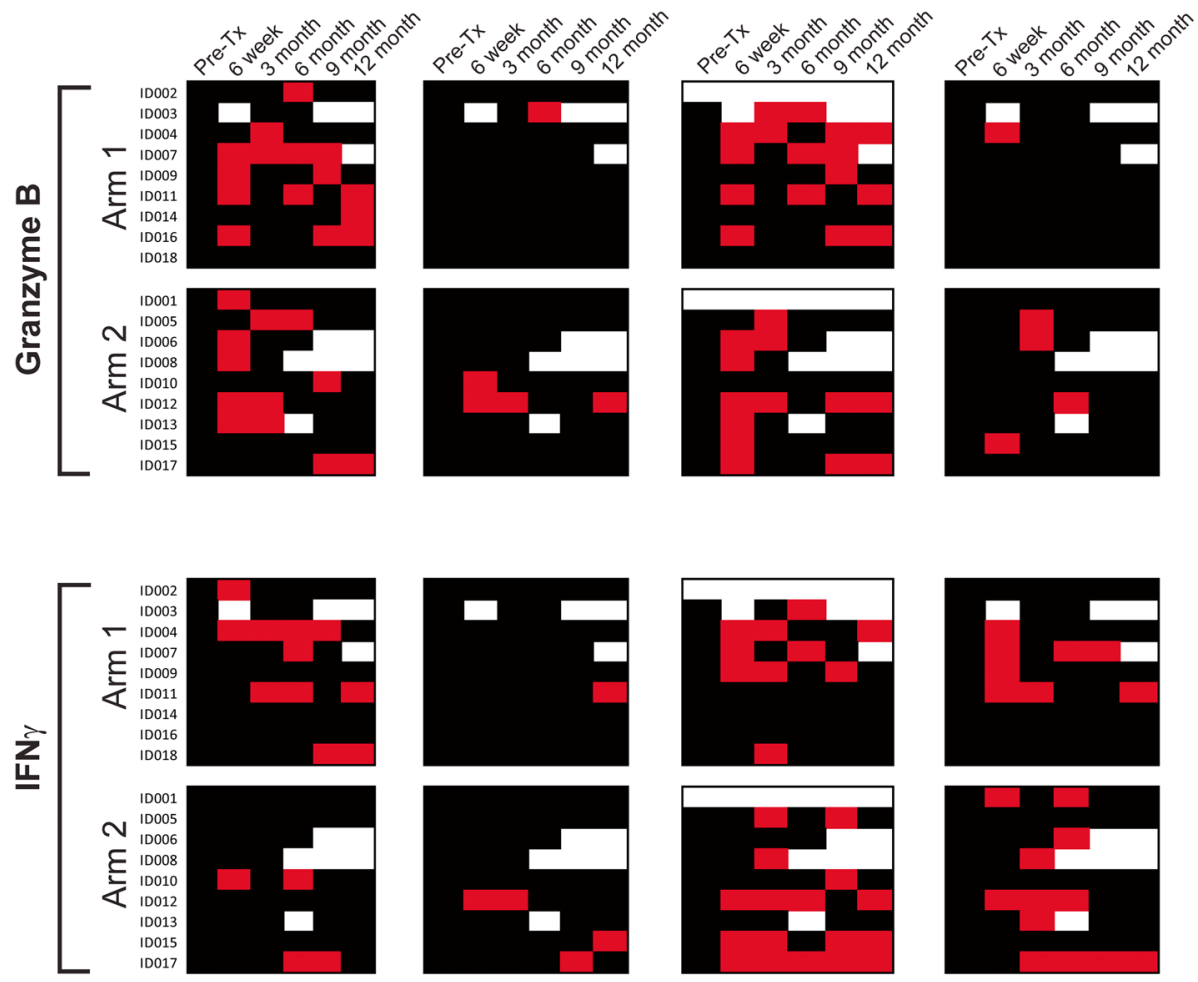

Fig. 2 Sipuleucel-T and DNA immunization elicits PAP-specific cellular immune responses. a ELISPOT was used to determine the frequency of antigen-specific IFNy-secreting T-cells over multiple time points. Shown are results for one patient (ID004) obtained in real-time at each time point. b ELISPOT was also used to determine the frequency of antigen-specific granzyme B-secreting T-cells over multiple time points for the same individual. Asterisks denote positive immune responses elicited, defined as an antigen-specific response (statistically higher than the media-only control, $p<0.05$ by t-test) that was at least 3-fold higher than baseline and with a frequency $>1: 100,000$ cells. c Shown are the comprehensive summary data from immune monitoring by evaluation for PAP-, PSA-, GM-CSF, or tetanus-specific immune responses as assessed by IFNy or granzyme B secretion by ELISPOT. A positive immune response (red) was defined as an antigen-specific response (statistically higher than the media-only control, $p<0.05$ by t-test) that was at least 3-fold higher than baseline and with a frequency $>1: 100,000$ cells. Black squares indicate a time point where an assessment was performed, but in which immune response criteria were not met. White squares indicate time points where no data was collected

also elicited to GM-CSF, and were not different with respect to treatment arm. Antibody responses to PAP, however, were of higher titer and higher frequency in patients treated in Arm 2.

As shown in Fig. 2c, IFN $\gamma$-secreting T-cell responses to PAP were detected in only 2 individuals (ID010 and ID017) in Arm 2 (with DNA vaccine). To characterize these responses over time, and to determine if different individual T-cell populations were elicited with sipuleucel-T compared with DNA, samples obtained at 6 months were stimulated in vitro with a panel of 94 15-mer peptides spanning the amino acid sequence of PAP, and then evaluated for individual peptide epitope specificity by ELISPOT. Epitope-specific T cells could not be identified for patient ID017. However, as shown in Fig. 4a, T cells specific for two peptides (p85 and 201) were identified for patient ID010 that were recognized after treatment but not before. Responses to these two peptides were then characterized over time. As shown in Fig. 4b, T cells specific for peptide 209 were detectable as early as 6 weeks, but T cells 
a

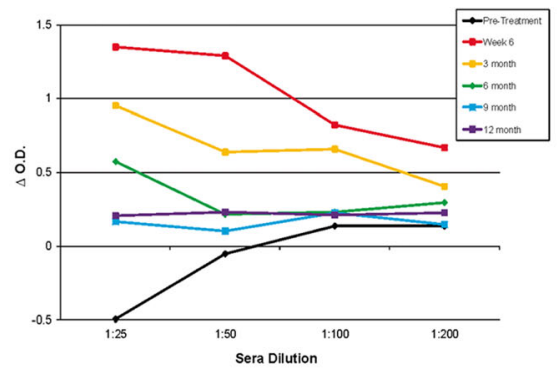

b

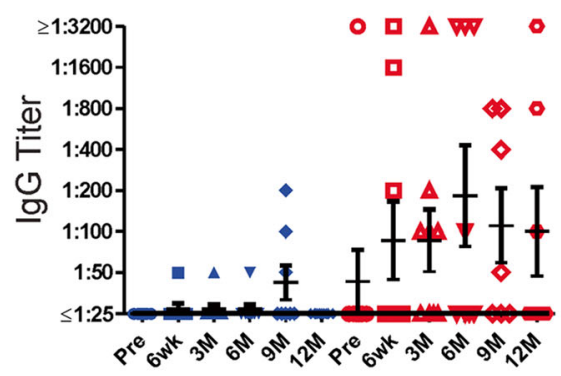

PSA

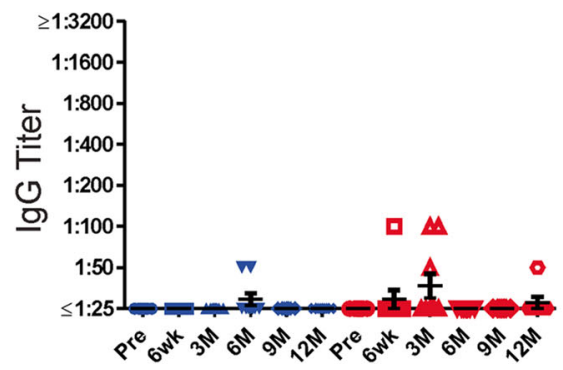

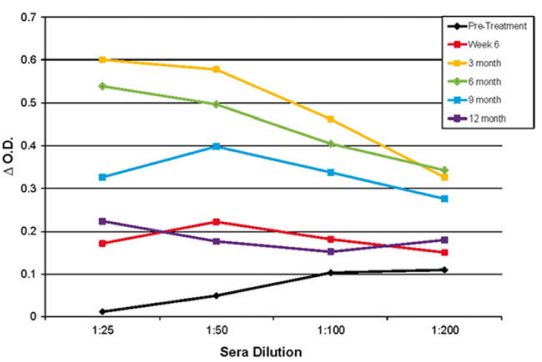

GM-CSF

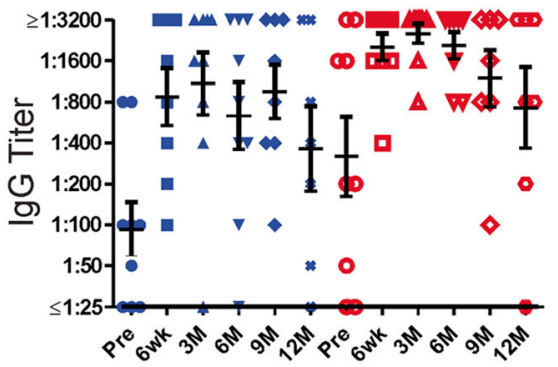

TET

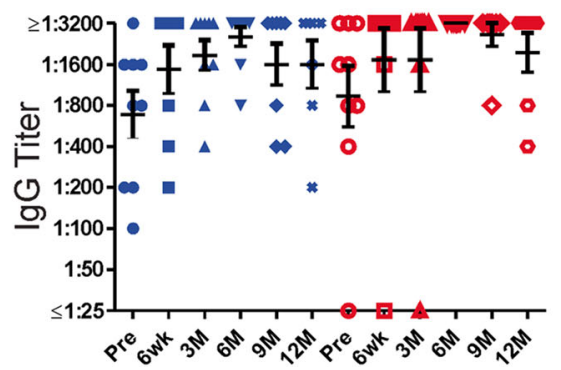

Fig. 3 Sipuleucel-T and DNA immunization elicit PAP-specific antibody responses. a Shown are results for indirect ELISA evaluating IgG responses to PAP for two individuals (ID010 (right) and ID015 (left)) at each time point at different sera dilutions. $\triangle$ O.D. represents the difference in optical density at each serum concentration for PAP relative to blank well. b Shown are lgG antibody titers to PAP, GM-CSF, PSA, and tetanus toxoid (TET) for all patients at each time point. Blue symbols represent patients treated in Arm 1, red symbols represent patients treated in Arm 2. Bars show the mean and standard error for each group

specific for peptide 85 were not detectable until 3 months. The timing of these responses suggests that sipuleucel-T and DNA vaccination elicited T cells specific for different epitopes, with $\mathrm{T}$ cells specific for an epitope contained within p209 elicited with sipuleucel-T, but another in p85 augmented with DNA vaccination.

To further characterize the antibody responses and determine if IgG responses to B cell epitopes similarly changed over time, antibody responses for four individuals from Arm 2 with the highest titer antibodies were evaluated to a panel of overlapping 16-mer peptides spanning the amino acid sequence of PAP. As demonstrated in Fig. 5a, IgG responses were detectable post-treatment that were not detectable pre-treatment, and regions of the protein recognized were not necessarily shared by different individuals. However, three individuals (ID010, ID013 and ID015) did have IgG responses to peptides within the same region (amino acids 177-232), and these were then characterized over time to determine if responses were associated with response to sipuleucel-T or DNA vaccine. As shown in Fig. 5b for patient ID010, IgG responses to the dominant peptides were detectable by ELISA at 6 weeks, and increased in titer by 3 months, suggesting responses were elicited with sipuleucel-T and further augmented with DNA vaccination. Of note, the antibody epitope recognized in this individual ( $\mathrm{p} 201-220)$ overlapped or was immediately proximal to the $\mathrm{T}$ cell epitope also elicited by sipuleucel-T (Fig. 4b). Antibody responses in all patients were determined by ELISA to be IgG, and predominantly IgG1 subtype (data not shown).

\section{Clinical evaluation}

In previous placebo-controlled randomized clinical trials conducted with sipuleucel- $\mathrm{T}$, there was not a significant 

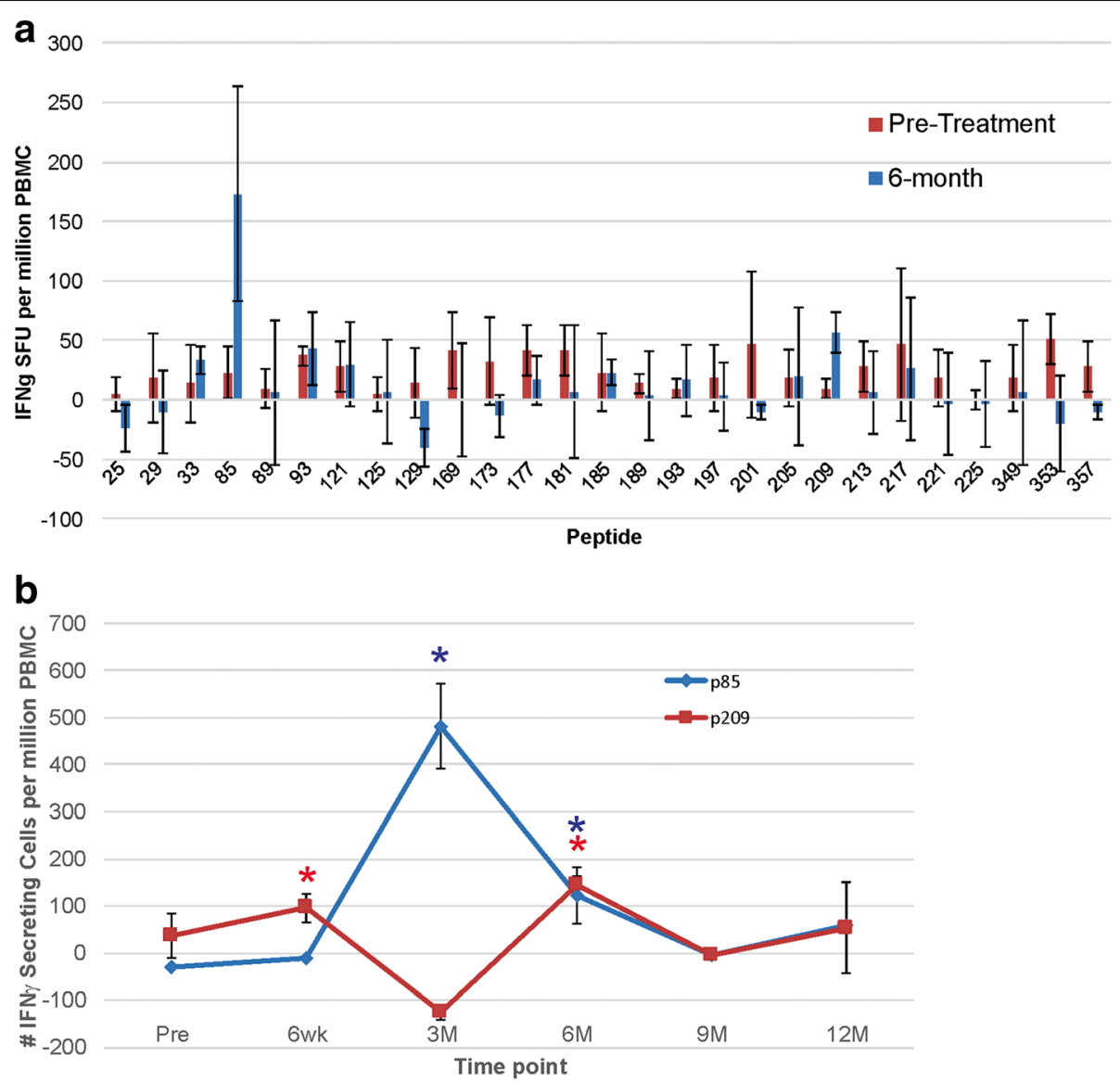

Fig. 4 Immune responses to PAP-derived peptides. a PBMC from patient ID010 were evaluated at baseline and 6 months for IFNY ELISPOT response to individual 15-mer peptides derived from the amino acid sequence of PAP. The peptide number indicates the starting amino acid from the PAP sequence of the 15-mer peptide. Shown are mean and standard deviation of IFNy spot-forming units (SFU) per million PBMC for results, conducted in triplicate for each peptide. b PBMC from patient ID010, obtained at the indicated time points, were stimulated in vitro with peptide p85 or p209, and then evaluated for IFNy release by ELISPOT. Asterisks indicate $p<0.05$ (t-test) by comparison with media only control

difference in median time to radiographic progression, which was approximately 12 weeks $[1,18]$. In order to account for this and possible delayed effects of treatment on progression, patients were evaluated for time to progression using scans obtained at month 3 as a new baseline scan. While the trial was not powered to detect difference in time to progression, as shown in Fig. 6a, there were no differences between study arms in terms of time to progression (median 161 days in Arm 1 vs. 164 days in Arm 2). Of note, however, two patients treated in Arm 2 (ID010 and ID015) had evidence of progression at month 3 compared to baseline, however then remained on trial without progression until month 9 and 12, respectively, at which point radiographic progression beyond month 3 was detected. All other patients with evidence of progression at month 3 had evidence of further progression by month 6 . Similarly, while the trial was not powered to detect differences in overall survival, no significant differences in overall survival between study arms were noted (Fig. 6b). Median overall survival was 715 days (24 months) in Arm
1 versus 901 (30 months) in Arm 2 (with DNA vaccine). As shown in Fig. 6c there were no differences observed in PSA kinetics with respect to study arm. PSA doubling times were calculated from PSA values obtained up to 6 months prior to treatment and up to 6 months from day 1 of study treatment. Pre-treatment PSA doubling time was 2.55 months for all patients (2.8 months Arm 1, 2.2 months Arm 2). There were no significant changes in PSA doubling time observed post-treatment (2.6 months overall, 2.5 months Arm 1, 2.6 months Arm 2).

\section{Discussion}

Heterologous prime-boost immunization strategies, in which two different vaccine types are used, each encoding the same antigen, have been demonstrated in many contexts to improve the immunological outcome of vaccination. Studies in preclinical models and human trials have shown increased antigen-specific T cells and/or antibodies using this approach in infectious disease and tumor systems [19-21]. Notably, in the case of viral or bacterial 


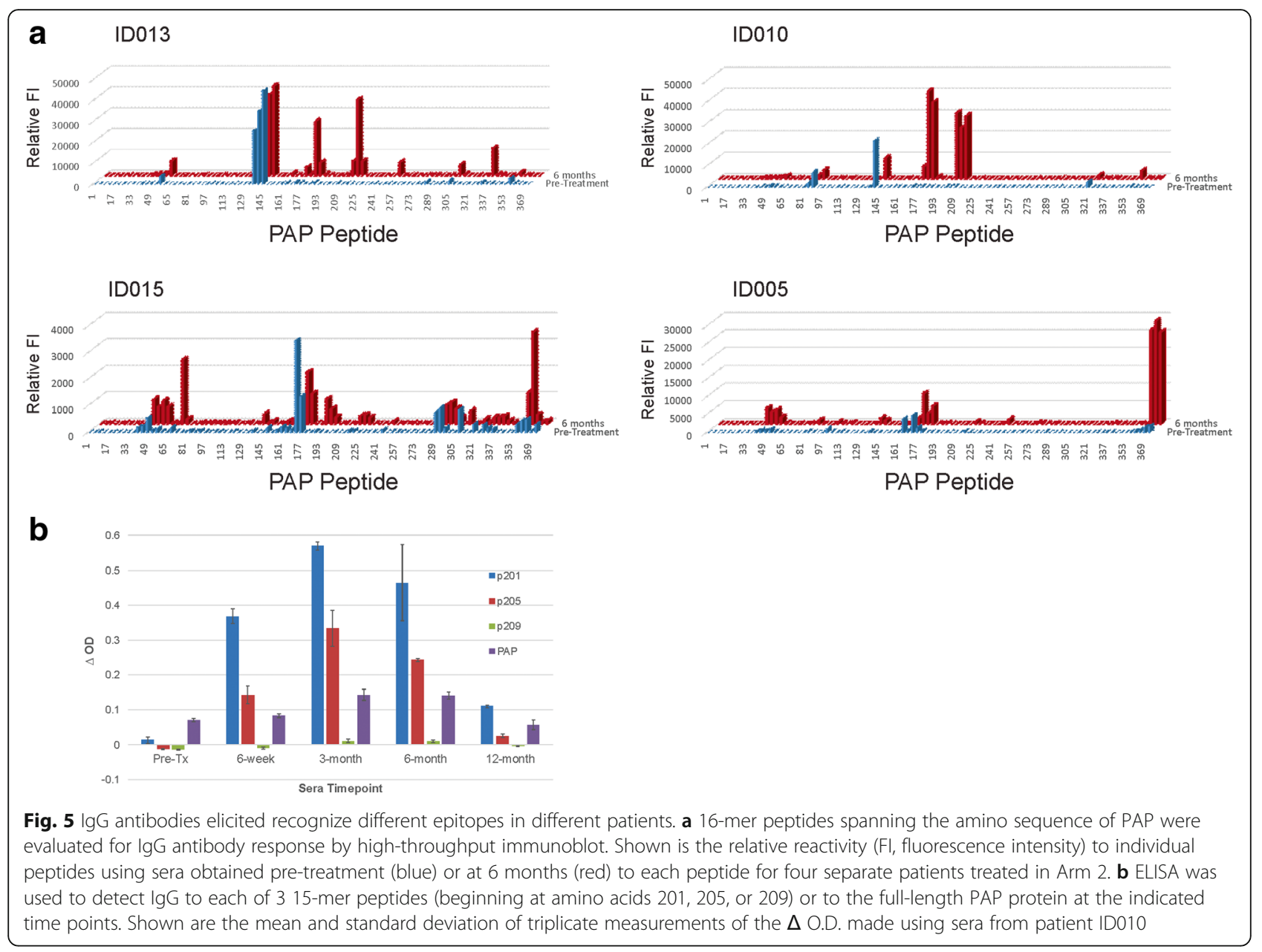

vector vaccines, the use of heterologous prime-boost approaches has been critical to avoid neutralizing immunity to the vector while augmenting immunity to the intended target antigen. This, in fact, was the approach used in the PSA-TRICOM vaccine targeting PSA as a prostate tumor antigen, using vaccinia virus encoding PSA as a priming immunization followed by booster immunizations with fowlpox encoding PSA [22]. We have previously investigated a vaccinia vector encoding PAP and found that multiple immunization with that vector elicited a dominant response to the vector, not the target antigen, and this could be circumvented by booster immunization with either PAP protein or DNA encoding PAP [10]. Given that DNA encoding PAP alone could elicit Th1-biased T cell immunity to PAP without eliciting vector-specific immunity, we have explored it in early clinical trials $[11,12]$. At present, the only FDA-approved anti-tumor vaccine is sipuleucel-T, a treatment for advanced prostate cancer that similarly targets the prostate-specific antigen PAP. Given the availability of two vaccines each targeting this tumor antigen, the current trial evaluated whether T-cell responses to PAP could be augmented using them in a prime-boost approach. We found that with this sequence of administration, with sipuleucel-T followed by DNA immunization, there was no evidence of increased Th1-biased response to PAP.

This is the first trial to evaluate long-term effector and memory $\mathrm{T}$ cell immunity to PAP following sipuleucel-T treatment. We found that IFN $\gamma$ - and granzyme Bsecreting $\mathrm{T}$ cells specific for PAP were amplified with treatment, and could be detected up to at least one year following treatment in some individuals. Of note, PAPspecific granzyme B-secreting immunity was detected in half of patients at week 6 after completing the sipuleucel-T infusions. Antibody and Th1-biased cellular responses were also detected to GM-CSF. This is not surprising, as the PA2024 antigen used for activation of autologous cells in the manufacture of sipuleucel-T is a fusion protein of PAP and GM-CSF. The finding in our study that IFN $\gamma$-secreting response specific for GM-CSF were detectable in several individuals $(5 / 16,31 \%)$ who did not have an IFN $\gamma$-secreting response specific for PAP likely accounts for previous findings that the frequency of responses to the PA2024 antigen are higher 

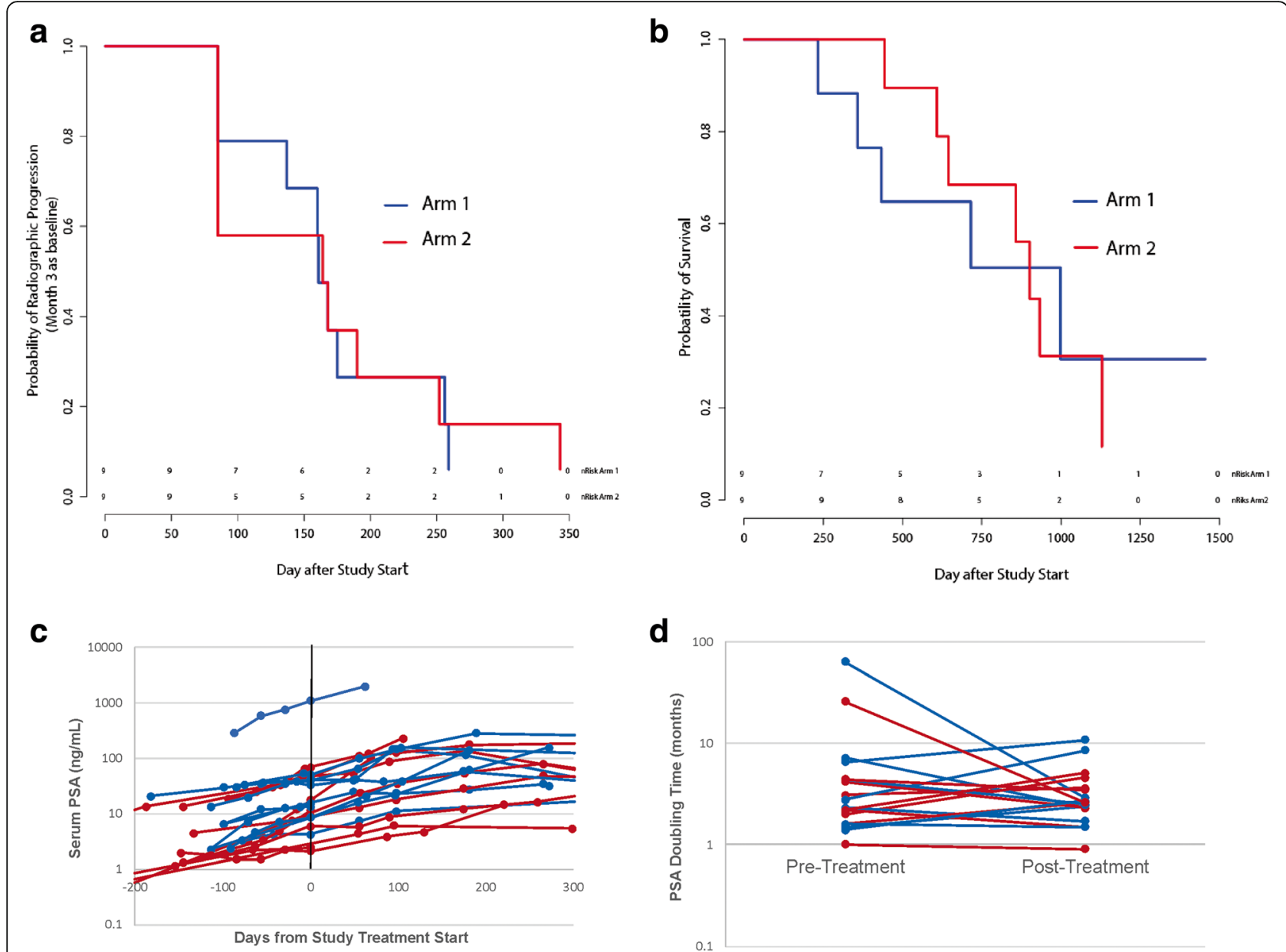

Fig. 6 Clinical outcomes. a Time to radiographic progression using staging obtained at month 3 as baseline for evaluation. b Overall survival. c Serum PSA values collected for each patient pre-treatment and up to one year. $\mathbf{d}$ Pre-treatment and post-treatment PSA doubling times. For each panel, blue lines indicate patients treated in Arm 1, red lines indicate patients treated in Arm 2

than those detected to the native PAP antigen $[1,8]$. That is, many patients likely develop immunity to the GM-CSF portion of the fusion protein. We have previously reported that immunity to GM-CSF can occur following immunization with GM-CSF protein, and to date there has been no evidence of adverse effect from immunity to GM-CSF [23].

This trial was not powered to detect differences in time to progression or overall survival, and no obvious trends were observed. Median overall survival was 28 months, which is consistent with previous trials conducted with sipuleucel-T in this patient population [18]. Embedded within the trial design was an attempt to determine if treatment might slow the progression of disease. Specifically, in previous trials using anti-tumor vaccines conducted in this population, the median progression-free survival was about 12 weeks, at the first radiographic imaging time point $[1,24]$. Treatment on the current trial was permitted beyond 12 weeks in order to determine if subsequent imaging showed stable disease, thus our results cannot be directly compared with previous studies using sipuleucel-T in terms of time to progression. Notwithstanding, using this approach, only two patients with evidence of progression at 3 months had stable disease after that, suggesting that delayed disease stability, if it occurs, is not common. Similarly, no differences were observed in pre-treatment and post-treatment PSA doubling times overall or for either treatment arm.

The trial was designed to test whether a DNA vaccine could boost cellular immunity elicited by sipuleucel-T. It was designed in this way given that sipuleucel- $T$ is an approved therapy, and we did not want to potentially delay administration of an approved treatment. In addition, a prescribed course of sipuleucel- $\mathrm{T}$ involves three administrations at 2-week intervals, and is not amenable to large schedule interruptions or retreatment at later time points. Thus, the simplest design was to use a DNA vaccine after completing sipuleucel-T treatment. In retrospect, this was likely not the optimal design. 
First, the majority of patients had disease progression requiring study discontinuation before receiving multiple DNA immunizations, suggesting that, although safe, it may not be clinically feasible to sequence vaccines alone in this patient population when progression occurs quickly. In addition, nearly all studies to date evaluating DNA vaccines in heterologous prime-boost approaches, whether in preclinical models or human trials, have demonstrated that a preferred sequence of immunization is using DNA as the priming immunization [25-30]. In fact, an early study demonstrated that DNA priming followed by a booster immunization with a herpes simplex viral protein elicited a Th1-biased immune response, whereas the opposite sequence elicited a Th2biased response [31]. Given that sipuleucel-T elicits both Th1 and Th2 immunity to PAP, we suspect this Th2 response was preferentially boosted with DNA leading to an increased IgG response. A preferred approach may have been to use the DNA immunization prior to sipuleucel-T. In preclinical studies using the same DNA vaccine encoding PAP or a Listeria monocytogenes vector encoding PAP, we have found that priming with DNA followed by Listeria boost, and not the opposite sequence, elicited the most robust Th1-biased cellular immunity and anti-tumor response (manuscript in preparation). Consequently, future studies will explore heterologous prime-boost approaches using DNA as the priming immunization.

\section{Conclusions}

Our findings demonstrate that delivery of two vaccines encoding the same target antigen, using a DNA vaccine as a booster vaccine following treatment with sipuleucel$\mathrm{T}$, is safe and can augment and diversify the type of immunity elicited with anti-tumor vaccination.

\section{Acknowledgments}

We are grateful for the assistance of the research staff of the UWHC infusion center, UW pharmacy research center, clinical research coordinators and staff, treating physicians, and the participation of the patients and families.

\section{Funding}

This work was supported by an investigator-initiated clinical trial award from Dendreon Corporation, and by National Institutes of Health P30 CA014520.

\section{Availability of data and materials}

The data generated and/or analyzed during this study are available from the corresponding author on reasonable request.

\section{Authors' contributions}

EW, LEJ, and LD conducted and analyzed laboratory studies described; JCE was study biostatistician during design and analysis; MJS and GL led and supervised clinical trial and conduct; DGM designed protocol and oversaw analysis; all authors contributed to the writing and approval of the final manuscript.

\section{Ethics approval and consent to participate}

The study protocol was reviewed and approved by all local (University of Wisconsin Human Subjects' Review Board (IRB), UW protocol CO11816), and federal (FDA, NIH Recombinant DNA Advisory Committee) entities. All patients gave written informed consent for participation. The trial national registration number is NCT01706458.

\section{Consent for publication}

Not applicable.

\section{Competing interests}

Douglas G. McNeel has ownership interest, has received research support, and serves as consultant to Madison Vaccines, Inc. which has licensed intellectual property related to this content. None of the other authors have relevant potential conflicts of interest.

\section{Publisher's Note}

Springer Nature remains neutral with regard to jurisdictional claims in published maps and institutional affiliations.

\section{Author details \\ 'University of Wisconsin Carbone Cancer Center, 1111 Highland Avenue, Madison, WI 53705, USA. ${ }^{2}$ Department of Biostatistics, University of Wisconsin, Madison, WI 53792, USA.}

Received: 18 January 2018 Accepted: 28 February 2018 Published online: 13 March 2018

\section{References}

1. Kantoff PW, Higano CS, Shore ND, Berger ER, Small EJ, Penson DF, Redfern $\mathrm{CH}$, Ferrari AC, Dreicer R, Sims RB, et al. Sipuleucel-T immunotherapy for castration-resistant prostate cancer. N Engl J Med. 2010;363:411-22.

2. Tannock IF, de Wit R, Berry WR, Horti J, Pluzanska A, Chi KN, Oudard S, Theodore C, James ND, Turesson I, et al. Docetaxel plus prednisone or mitoxantrone plus prednisone for advanced prostate cancer. N Engl J Med. 2004;351:1502-12.

3. Petrylak DP, Tangen CM, Hussain MH, Lara PN Jr, Jones JA, Taplin ME, Burch PA, Berry D, Moinpour C, Kohli M, et al. Docetaxel and estramustine compared with mitoxantrone and prednisone for advanced refractory prostate cancer. N Engl J Med. 2004;351:1513-20.

4. de Bono JS, Oudard S, Ozguroglu M, Hansen S, Machiels JP, Kocak I, Gravis G, Bodrogi I, Mackenzie MJ, Shen L, et al. Prednisone plus cabazitaxel or mitoxantrone for metastatic castration-resistant prostate cancer progressing after docetaxel treatment: a randomised open-label trial. Lancet. 2010;376: $1147-54$.

5. de Bono JS, Logothetis CJ, Molina A, Fizazi K, North S, Chu L, Chi KN, Jones RJ, Goodman OB Jr, Saad F, et al. Abiraterone and increased survival in metastatic prostate cancer. N Engl J Med. 2011;364:1995-2005.

6. Parker C, Nilsson S, Heinrich D, Helle SI, O'Sullivan JM, Fossa SD, Chodacki A, Wiechno P, Logue J, Seke M, et al. Alpha emitter radium-223 and survival in metastatic prostate cancer. N Engl J Med. 2013;369:213-23.

7. Scher HI, Fizazi K, Saad F, Taplin ME, Sternberg CN, Miller K, de Wit R, Mulders P, Chi KN, Shore ND, et al. Increased survival with enzalutamide in prostate cancer after chemotherapy. N Engl J Med. 2012;367:1187-97.

8. Sheikh NA, Petrylak D, Kantoff PW, Dela Rosa C, Stewart FP, Kuan LY, Whitmore JB, Trager JB, Poehlein CH, Frohlich MW, Urdal DL. Sipuleucel-T immune parameters correlate with survival: an analysis of the randomized phase 3 clinical trials in men with castration-resistant prostate cancer. Cancer Immunol Immunother. 2013;62:137-47.

9. Schellhammer PF, Chodak G, Whitmore JB, Sims R, Frohlich MW, Kantoff PW. Lower baseline prostate-specific antigen is associated with a greater overall survival benefit from sipuleucel-T in the immunotherapy for prostate adenocarcinoma treatment (IMPACT) trial. Urology. 2013;81:1297-302.

10. Johnson LE, Frye TP, Chinnasamy N, Chinnasamy D, McNeel DG. Plasmid DNA vaccine encoding prostatic acid phosphatase is effective in eliciting autologous antigen-specific CD8+ T cells. Cancer Immunol Immunother. 2007;56:885-95

11. McNeel DG, Dunphy EJ, Davies JG, Frye TP, Johnson LE, Staab MJ, Horvath DL, Straus J, Alberti D, Marnocha R, et al. Safety and immunological efficacy of a DNA vaccine encoding prostatic acid phosphatase in patients with stage D0 prostate cancer. J Clin Oncol. 2009;27:4047-54.

12. McNeel DG, Becker JT, Eickhoff JC, Johnson LE, Bradley E, Pohlkamp I, Staab MJ, Liu G, Wilding G, Olson BM. Real-time immune monitoring to guide plasmid DNA vaccination schedule targeting prostatic acid phosphatase in 
patients with castration-resistant prostate cancer. Clin Cancer Res. 2014;20: 3692-704.

13. Becker JT, Olson BM, Johnson LE, Davies JG, Dunphy EJ, McNeel DG. DNA vaccine encoding prostatic acid phosphatase (PAP) elicits long-term T-cell responses in patients with recurrent prostate cancer. J Immunother. 2010; 33:639-47.

14. Johnson LE, Frye TP, Arnot AR, Marquette C, Couture LA, Gendron-Fitzpatrick A, McNeel DG. Safety and immunological efficacy of a prostate cancer plasmid DNA vaccine encoding prostatic acid phosphatase (PAP). Vaccine. 2006;24:293-303.

15. Scher HI, Halabi S, Tannock I, Morris M, Sternberg CN, Carducci MA, Eisenberger MA, Higano C, Bubley GJ, Dreicer R, et al. Design and end points of clinical trials for patients with progressive prostate cancer and castrate levels of testosterone: recommendations of the prostate cancer clinical trials working group. J Clin Oncol. 2008;26:1148-59.

16. McNeel DG, Nguyen LD, Storer BE, Vessella R, Lange PH, Disis ML. Antibody immunity to prostate cancer-associated antigens can be detected in the serum of patients with prostate cancer. J Urol. 2000;164:1825-9.

17. Forsstrom B, Axnas BB, Stengele KP, Buhler J, Albert TJ, Richmond TA, Hu FJ, Nilsson P, Hudson EP, Rockberg J, Uhlen M. Proteome-wide epitope mapping of antibodies using ultra-dense peptide arrays. Mol Cell Proteomics. 2014:13:1585-97.

18. Higano CS, Schellhammer PF, Small EJ, Burch PA, Nemunaitis J, Yuh L, Provost N, Frohlich MW. Integrated data from 2 randomized, double-blind, placebo-controlled, phase 3 trials of active cellular immunotherapy with sipuleucel-T in advanced prostate cancer. Cancer. 2009;115:3670-9.

19. Schneider J, Gilbert SC, Hannan CM, Degano P, Prieur E, Sheu EG, Plebanski $\mathrm{M}$, Hill AV. Induction of CD8+ T cells using heterologous prime-boost immunisation strategies. Immunol Rev. 1999;170:29-38.

20. Lin T, Liang S, Meng F, Han Q, Guo C, Sun L, Chen Y, Liu Z, Yu Z, Xie H, et al. Enhanced immunogenicity and antitumour effects with heterologous prime-boost regime using vaccines based on MG7-ag mimotope of gastric cancer. Clin Exp Immunol. 2006;144:319-25.

21. Ogwang C, Afolabi M, Kimani D, Jagne YJ, Sheehy SH, Bliss CM, Duncan CJ, Collins KA, Garcia Knight MA, Kimani E, et al. Safety and immunogenicity of heterologous prime-boost immunisation with plasmodium falciparum malaria candidate vaccines, ChAd63 ME-TRAP and MVA ME-TRAP, in healthy Gambian and Kenyan adults. PLoS One. 2013;8:e57726.

22. Madan RA, Arlen PM, Mohebtash M, Hodge JW, Gulley JL. Prostvac-VF: a vector-based vaccine targeting PSA in prostate cancer. Expert Opin Investig Drugs. 2009;18:1001-11.

23. McNeel DG, Schiffman K, Disis ML. Immunization with recombinant human granulocyte-macrophage colony-stimulating factor as a vaccine adjuvant elicits both a cellular and humoral response to recombinant human granulocyte-macrophage colony-stimulating factor. Blood. 1999;93:2653-9.

24. Kantoff PW, Schuetz TJ, Blumenstein BA, Glode LM, Bilhartz DL, Wyand M, Manson K, Panicali DL, Laus R, Schlom J, et al. Overall survival analysis of a phase II randomized controlled trial of a Poxviral-based PSA-targeted immunotherapy in metastatic castration-resistant prostate cancer. J Clin Oncol. 2010;28:1099-105.

25. Xiang ZQ, Pasquini S, Ertl HC. Induction of genital immunity by DNA priming and intranasal booster immunization with a replication-defective adenoviral recombinant. J Immunol. 1999;162:6716-23.

26. Wang QM, Sun SH, Hu ZL, Yin M, Xiao CJ, Zhang JC. Improved immunogenicity of a tuberculosis DNA vaccine encoding ESAT6 by DNA priming and protein boosting. Vaccine. 2004;22:3622-7.

27. Sedegah M, Brice GT, Rogers WO, Doolan DL, Charoenvit Y, Jones TR, Majam VF, Belmonte A, Lu M, Belmonte M, et al. Persistence of protective immunity to malaria induced by DNA priming and poxvirus boosting: characterization of effector and memory CD8(+)-T-cell populations. Infect Immun. 2002;70:3493-9.

28. Khurana S, Wu J, Dimitrova M, King LR, Manischewitz J, Graham BS, Ledgerwood JE, Golding H. DNA priming prior to inactivated influenza a(H5N1) vaccination expands the antibody epitope repertoire and increases affinity maturation in a boost-interval-dependent manner in adults. J Infect Dis. 2013;208:413-7.

29. Joachim A, Nilsson C, Aboud S, Bakari M, Lyamuya EF, Robb ML, Marovich MA, Earl P, Moss B, Ochsenbauer C, et al. Potent functional antibody responses elicited by HIV-I DNA priming and boosting with heterologous HIV-1 recombinant MVA in healthy Tanzanian adults. PLoS One. 2015;10:e01 18486.

30. Ledgerwood JE, Zephir K, Hu Z, Wei CJ, Chang L, Enama ME, Hendel CS, Sitar S, Bailer RT, Koup RA, et al. Prime-boost interval matters: a randomized phase 1 study to identify the minimum interval necessary to observe the H5 DNA influenza vaccine priming effect. J Infect Dis. 2013;208:418-22.

31. Sin Jl, Bagarazzi M, Pachuk C, Weiner DB. DNA priming-protein boosting enhances both antigen-specific antibody and Th1-type cellular immune responses in a murine herpes simplex virus-2 $\mathrm{gD}$ vaccine model. DNA Cell Biol. 1999;18:771-9.

\section{Submit your next manuscript to BioMed Central and we will help you at every step:}

- We accept pre-submission inquiries

- Our selector tool helps you to find the most relevant journal

- We provide round the clock customer support

- Convenient online submission

- Thorough peer review

- Inclusion in PubMed and all major indexing services

- Maximum visibility for your research

Submit your manuscript at www.biomedcentral.com/submit

) Biomed Central 